\title{
Impact of residual ridge anatomy on masticatory efficiency of conventional complete denture users
}

\author{
Impacto da anatomia do rebordo residual na eficiência \\ mastigatória em usuários de próteses totais convencionais
}

\author{
Maria de Fátima Trindade Pinto CAMPOS1 ID https://orcid.org/0000-0003-1196-2451 \\ Laércio Almeida de MELO' ID https://orcid.org/0000-0002-9276-0116 \\ Roberto Fagner Felix ARAÚJO' ${ }^{1}$ iD https://orcid.org/0000-0002-7418-8291 \\ Annie Karoline Bezerra de MEDEIROS' ID https://orcid.org/0000-0001-5137-2179 \\ Adriana da Fonte Porto CARREIRO' ${ }^{1}$ iD https://orcid.org/0000-0002-0833-1926
}

\section{ABSTRACT}

Objective: The aim of this cross-sectional study was to evaluate the anatomical characteristics of edentulous residual ridges in stone casts of complete dentures users and assess correlations with masticatory efficiency. Methods: The sample included 74 study casts, of which 37 were higher and 37 bottom. Measurements were performed using a drypoint compass and a transparent ruler. Arches and ridges of maxillae and mandibles were classified into small, medium, and large. Masticatory efficiency was obtained by the sieve method with the old prostheses and 3 months after placement of new prostheses. The correlations between the anatomical variables of the ridges and arches (height, width and size) and masticatory efficiency were verified by the Spearman correlation test. Significant differences in masticatory efficiencies were assessed by the Wilcoxon test. Results: People with larger maxillary alveolar ridge presented better masticatory performance with old and new dentures. There was no correlation between maxillary ridge width and size with masticatory efficiency, but a correlation was found between maxillary arch width and masticatory efficiency evaluated with the old dentures. Conclusion: With the new dentures, the correlation had a tendency for significance. For the mandible, no correlation was found between height, width, and size of the ridge or with width, length, and size of the arch and masticatory efficiency. In addition, there was no significant difference between masticatory efficiencies evaluated with the old and new prostheses. For the maxilla, ridge height and arch width influence masticatory efficiency. For the mandible, the anatomy had little influence on masticatory performance.

Indexing terms: Alveolar ridge. Complete denture. Mastication.

\section{RESUMO}

Objetivo: Este estudo transversal objetivou avaliar as características anatômicas de rebordos residuais de usuários de próteses totais em gesso pedra e avaliar correlações com a eficiência mastigatória. Métodos: A amostra incluiu 74 modelos de estudo, sendo 37 superiores e 37 inferiores. As medidas foram realizadas com um compasso de ponta seca e régua transparente. Os arcos e rebordos da maxila e mandibula foram classificados em pequenos, médios e grandes. A eficiência mastigatória foi obtida pelo método da peneira

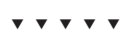

1 Universidade Federal do Rio Grande do Norte, Departamento de Odontologia. Avenida Senador Salgado Filho, 1787, Lagoa Nova, 59056-000, Natal, RN, Brasil. Correspondence to: MFTP CAMPOS. E-mail: <fatimacampos25@yahoo.com.br>

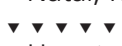

Campos MFTP, Melo LA, Araújo RFF, Medeiros AKB, Carreiro AFP. Impact of residual ridge anatomy on masticatory efficiency of conventional complete denture users. RGO, Rev Gaúch Odontol. 2021;69:e20210059. http://dx.doi.org/10.1590/1981-863720210005920200059 
com as próteses antigas e 3 meses após a instalação das próteses novas. As correlações entre as variáveis anatômicas dos rebordos e arcos (altura, largura e tamanho) e a eficiência mastigatória foram verificadas pelo teste Spearman. Diferenças significativas nas eficiências mastigatórias foram avaliadas pelo teste de Wilcoxon. Resultados: Pessoas com crista alveolar maxilar alta apresentaram melhor desempenho mastigatório com próteses novas e antigas. Não houve correlação entre a largura e o tamanho da crista maxilar com a eficiência mastigatória, mas foi encontrada uma correlação entre a largura do arco maxilar e a eficiência mastigatória avaliadas com as próteses antigas. Para a mandíbula, não foi encontrada correlação entre altura, largura e tamanho da crista ou com largura, comprimento e tamanho do arco e eficiência mastigatória. Além disso, não houve diferença significativa entre as eficiências mastigatórias avaliadas com as próteses antigas e novas. Conclusão: Para a maxila, a altura da crista e a largura do arco influenciam a eficiência mastigatória. Para a mandibula, a anatomia teve pouca influência no desempenho mastigatório.

Termos de indexação: Rebordo alveolar. Prótese total. Mastigação.

\section{INTRODUCTION}

One of the objectives of oral rehabilitation with conventional complete dentures is the restoration of masticatory function. The resorption of the alveolar bone is a continuous, chronic, progressive, irreversible and cumulative process throughout life [1-3]. When bone resorption is associated with unfavorable mechanical conditions of the prosthesis, decreased adaptation and retention may occur $[3,4]$. These factors may interfere with the masticatory function, especially in patients with thin, friable mucosa [4]. To minimize these consequences and increase patient satisfaction, the best possible prostheses should be made, which is dependent on a careful examination of the ridge anatomy $[5,6]$.

Some studies have found an association between residual ridge anatomy and masticatory efficiency in complete denture users [7-9]. Van der Bilt found that the basal seat of dentures was correlated with masticatory efficiency, but this study used natural food to test efficiency, which is a limitation since the generated data are difficult to reproduce due to the influence of seasonal and geographic factors [10].

Other studies $[8,9]$ assessed the correlation of masticatory efficiency with the size of the basal seat area of complete dentures by applying questionnaires, which are characterized by subjectivity 10 and favor the induction of bias, masking the actual data [8-11]. Among the available methods to evaluate masticatory efficiency, the sieve method, using Optocal as artificial food, is considered the gold standard for its objectivity, simplicity, and easy reproducibility $[5,12,13]$.

Due to the above limitations of previous studies and to the importance of studying the residual ridge anatomy to achieve the best treatment results for edentulous patients, the present study aimed to evaluate the correlation between the anatomical variables of the ridges (height, width, and size of ridges, and length, width, and size of maxillary and mandibular arches) and masticatory efficiency of people wearing old and new complete dentures.

\section{METHODS}

\section{Study design}

This was a cross-sectional study with a time series, conducted at the Department of Dentistry of the Federal University of Rio Grande do Norte (UFRN). This study was approved by the Research Ethics Committee of the institution under protocol 1.043.549/2015.

\section{Participants}

A convenience sample of patients that sought the institution's service to replace their dentures was used. Patients were invited to participate in the study from February 2014 to December 2015 and, if accepting, they signed the free and informed consent term. Thus, 37 patients and their 74 anatomical stone casts (higher and bottom) were included in this study. Masticatory efficiency was evaluated in two time-points: with the old prostheses (T1) and after 3 months wearing the new prostheses (T2). These 3 months correspond to the period of adaptation to the new prostheses. At T1, 37 patients were evaluated and at T2, 21 patients were evaluated.

\section{Data collection}

The masticatory efficiency values at $\mathrm{T} 1$ and the anatomical measurements of the stone casts were 
performed by a different researcher than the one who carried out the molding to obtain the study casts.

\section{Manufacture of stone models}

Casts were obtained from anatomical moldings with the purpose of making new prostheses. The moldings were made with stock trays (Tecnodent, São Paulo, Brazil) for edentulous ridges and customized with Newwax utility wax (Technew, Rio de Janeiro, Brazil), using irreversible hydrocolloid Jeltrate (Dentsply, Petrópolis, Brazil) for the higher ridge and condensation silicon Silon 2 APS (Dentsply, Petrópolis, Brazil) for the bottom ridge. Then, moldings were cast with a gypsum stone (Herodent, Rio de Janeiro, Brazil) and trimmed using a trimming machine (DCL, São Paulo, Brazil).

\section{Measurement of stone casts}

The methodology used by Pietrokovski et al. [2] was applied. Initially, an intra-examiner calibration was performed: ten casts were measured at intervals of one week, obtaining a Kappa value greater than 0.8 , indicating an excellent agreement $(K=0.981)$. Thus, the bearing area was delimited and maxillary and mandibular models were measured using a drypoint compass (JON-São PauloBRAZIL) and a 30-millimeter transparent ruler (TRIDENTItapuí-São Paulo, Brazil) (figure 1).

\section{Size of maxillary and mandibular arches}

The size of the edentulous arches was obtained by measuring the length of the midline and the width as seen in Figure 2. For the maxilla, the length was obtained by
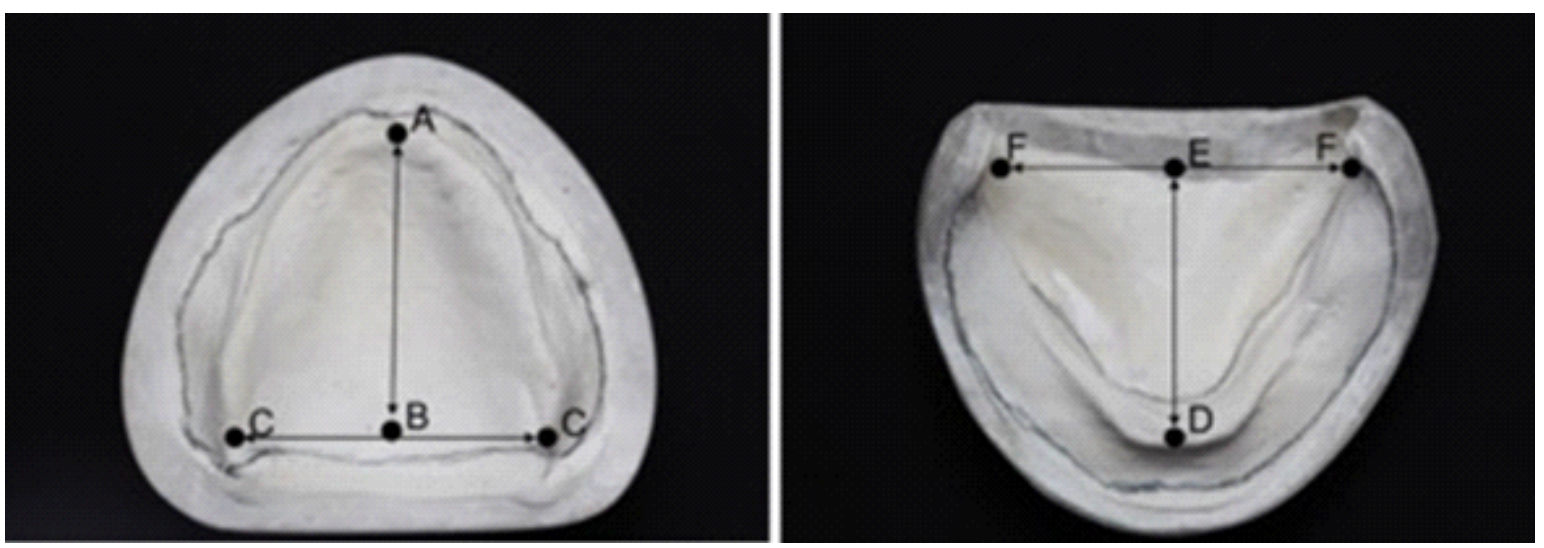

Figure 1. Points and lines used for length and width measurements of the maxillary and mandibular arch. (A) Incisive papilla; (B) Middle point between the maxillary tuberosities; (C) Maxillary tuberosities; (D) Middle point in the incisive region; (E) Middle point between the retromolar papillae; and (F) Retromolar papillae.
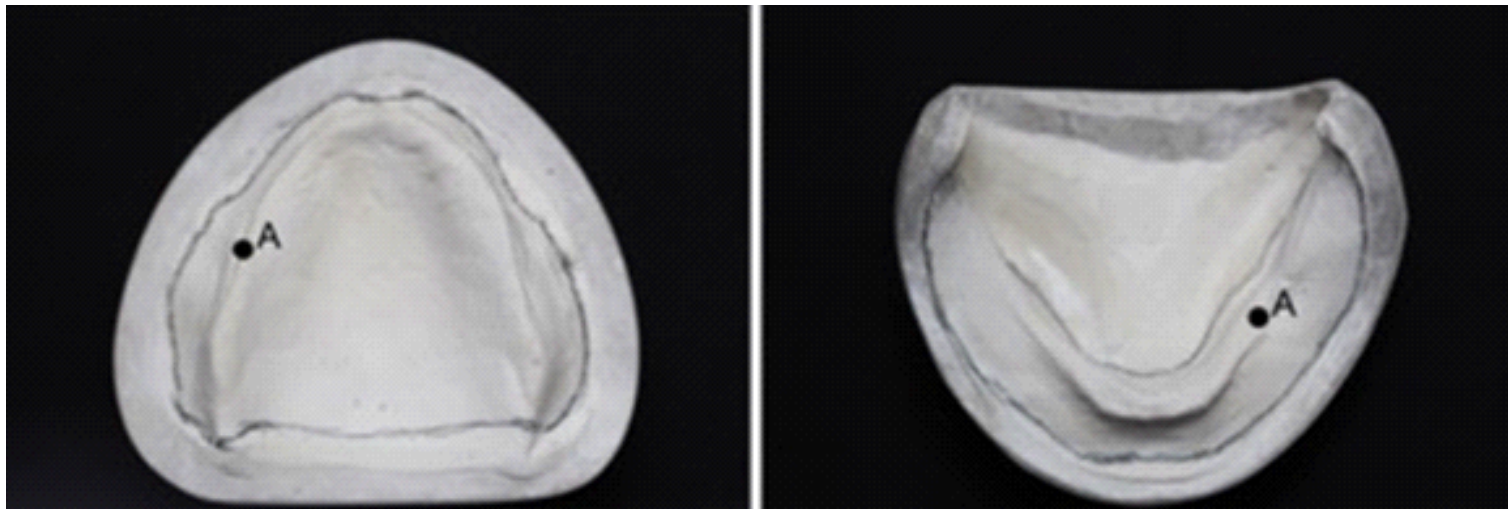

Figure 2. (A) Middle point of the ridge representing the premolar region for height and width measurements of the residual crest of the maxillary and mandibular ridge. 
measuring the distance from point A to point $B$ and width was obtained from the distance between the 2 points $C$. Likewise, the length of the mandibular arch was obtained by measuring the distance from point $D$ to $E$, and its width by the distance between the points $F$ [14].

The values were transformed into indices to categorize the arches into three sizes using the following formula: arch width $\times 100$ divided by arch length. Thus, the maxilla and the mandible arches were classified as small (<79), medium (80-89), and large (>90).

\section{Size of the maxillary and mandibular residual ridges}

Measurements of the height and width of the residual ridges were performed from a chosen midpoint on the ridge in the premolar region - following the methodology of the study by Pietrokovski et al. [15] (figure 3). The maxillary residual ridge height was measured as the linear distance between points $A$ and $B$ and the width between points $B$ and $C$. The height of the mandibular residual ridge was measured as the linear distance between points $D$ and $E$ and the width between points $E$ and $F$. The values found were also transformed into indices, following the formula: ridge width $\times 100$ divided by the ridge height. According to the results of the indices, the residual alveolar
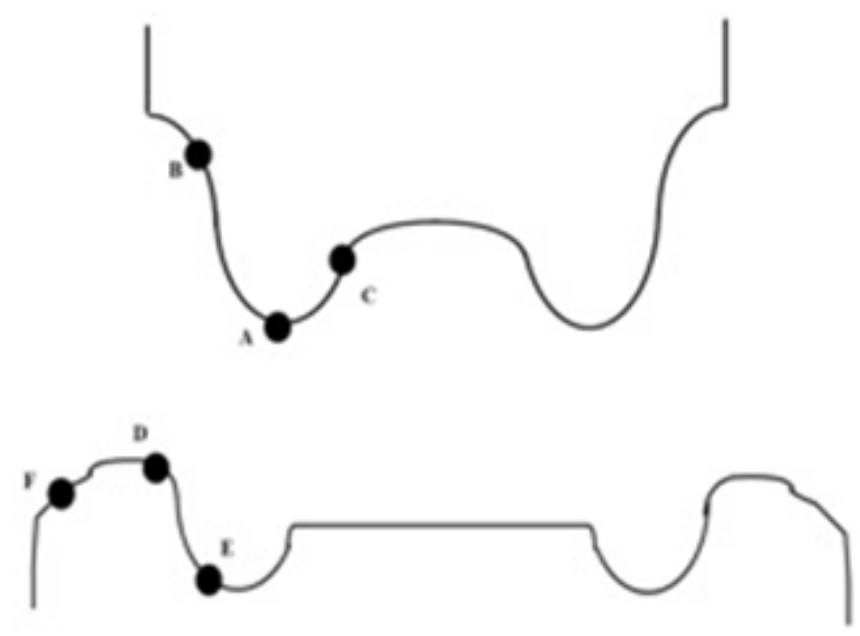

Figure 3. Height and width measurements of the residual maxillary and mandibular ridges. A) Highest point of maxillary residual ridge; (B) Deepest point of the upper buccal sulcus; (C) Location of point $B$ in the hard palate; (D) Highest point of mandibular residual ridge; (E) Limit between the ridge and floor of the mouth; and (F) Deepest point in lower buccal groove relative to point $\mathrm{E}$. ridges were classified as small (<69), median (70-79), and large (> 80), separately for the maxilla and mandible.

\section{Masticatory efficiency}

For the analysis of masticatory efficiency (ME), the methodology recommended by Slagter et al. [11], which consists of patients chewing pieces of the test food called Optocal (53 g Optosil Comfort $\AA$ (Heraeus Kulzer) condensation silicone, $1.43 \mathrm{~g}$ catalyst paste, 25 $\mathrm{g}$ toothpaste, $3 \mathrm{~g}$ vaseline, $8 \mathrm{~g}$ dental plaster, and $4 \mathrm{~g}$ alginate). The ME was evaluated after chewing and sieving the artificial food Optocal. The food was divided into packs of $3 \mathrm{~g}$ (17 cubes). During masticatory test, the patients were informed to perform a total of 20 masticatory cycles. The chewed food was then manipulated on a set of 8 decreasing granulometric sieves (Berte ${ }^{\circledR}$ ) with openings of $0.5,0.71,1,1.4,2,2.8,4$, and $5.6 \mathrm{~mm}$. The food removed from each sieve was weighed on a precision analytical scale (SHIMADZU do Brazil).

\section{Statistical analysis}

A database was created in Microsoft Excel 2013 software for entering the collected data, which were later transferred to SPSS version 20.0 for Windows for quantitative statistical analysis. Initially, a descriptive analysis of the data was performed. Then, Sperman correlation coefficient was used to verify the correlation between the anatomical variables of the ridges (height, width, and size of ridges and length, width, and size of the maxillary and mandibular arches) and masticatory efficiency of complete dentures users. To verify the difference between masticatory efficiencies of old and new prostheses, the Wilcoxon test was used. For both tests, a significance level of $5 \%$ was adopted.

\section{RESULTS}

Initially, data were collected on masticatory efficiency and measurements of the anatomical casts of 37 participants. The patients had a mean age of 67.9 years $( \pm 9.46)$ and the majority were female (83\%).

Maxillary arches classified as large were $83.8 \%$ of the sample, while $100 \%$ of the patients had a large mandibular arch $(n=37)$. Regarding the residual ridges, 
there was a predominance of large sizes in the maxilla $(82.8 \%)$ as well as in the mandible $(62.1 \%)$.

The mean value of masticatory efficiency with the old prostheses was $6.17 \mathrm{~mm}( \pm 0.87)$, ranging from 4.07 to $7.07 \mathrm{~mm}$. However, only 21 patients had their masticatory efficiency evaluated with new prostheses, for which the mean was $6.18 \mathrm{~mm}( \pm 1.29)$, varying from 2.98 to 7.71 . There was no significant difference between masticatory efficiencies evaluated with old and new prostheses $(p=0.615)$ (table 1).

With respect to ridge anatomy, those who had greater height of the maxillary alveolar crest presented better masticatory performance than those with lower heights using old $(p=0.026)$ and new ( $p=0.041)$ prostheses. There was no correlation between the width and size of the maxillary crest with masticatory efficiency of the old and new prostheses. However, a significant correlation between maxillary arch width and masticatory efficiency evaluated with the old prostheses was found $(p=0.004)$. With the new prostheses, this correlation had a tendency for significance $(p=0.087)$. For the mandible, there was no correlation between height, width, and crest size with masticatory efficiency either with old or new prostheses (tables 2 and 3).

Table 1. Masticatory efficiency with old prostheses and three months after the installation of new prostheses.

\begin{tabular}{lcccccc}
\hline & \multicolumn{2}{c}{ Old prostheses } & & \multicolumn{2}{c}{ New prostheses } \\
\cline { 2 - 3 } & $\mathrm{n}$ & Median (Q25-Q75) & & $\mathrm{n}$ & Median (Q25-Q75) \\
\hline Masticatory efficiency & 21 & $6.38(6.00-6.77)$ & & 21 & 6.55 (5.93-6.88) & 0.615 \\
\hline
\end{tabular}

Note: Wilcoxon non-parametric test.

Table 2. Correlations between height, width, and size of the ridge crests and the median particle diameter (X50) with old prostheses $(n=37)$ and after three months wearing the new prosthesis $(n=21)$.

\begin{tabular}{lcccc}
\hline \multirow{2}{*}{ Parameters } & \multicolumn{2}{c}{ X50 old prostheses } & & \multicolumn{2}{c}{ X50 new prostheses } \\
\cline { 2 - 4 } \cline { 4 - 5 } Maxillary crest height & rho & -0.365 & 0.026 & rho \\
Mandibular crest height & -0.117 & 0.492 & -0.438 & 0.041 \\
Maxillary crest width & -0.245 & 0.143 & -0.343 & -0.268 \\
Mandibular ridge width & -0.032 & 0.853 & -0.263 & 0.240 \\
Maxillary crest size & 0.20 & 0.907 & 0.109 & 0.249 \\
Mandibular crest size & -0.156 & 0.358 & & 0.160 \\
\hline
\end{tabular}

Note: Spearman correlation.

Table 3. Correlations between length and size of arches and chewed particle diameter $(X 50)$ with old prostheses ( $\mathrm{n}=37$ ) and after three months wearing new prostheses $(n=21)$.

\begin{tabular}{|c|c|c|c|c|}
\hline \multirow{2}{*}{ Parameters } & \multicolumn{2}{|c|}{ X50 old prostheses } & \multicolumn{2}{|c|}{ X50 new prostheses } \\
\hline & rho & $\mathrm{p}$ & rho & $\mathrm{p}$ \\
\hline Length of maxillary arch & -0.056 & 0.743 & -0.161 & 0.487 \\
\hline Length of mandibular arch & -0.017 & 0.922 & -0.196 & 0.396 \\
\hline Maxillary arch width & -0.458 & 0.004 & -0.383 & 0.087 \\
\hline Mandibular arch width & -0.117 & 0.492 & -0.233 & 0.309 \\
\hline Maxillary arch size & -0.297 & 0.074 & -0.049 & 0.834 \\
\hline Mandibular arch size & -0.012 & 0.943 & -0.034 & 0.884 \\
\hline
\end{tabular}

Note: Spearman correlation. 


\section{DISCUSSION}

The present study sought to evaluate the correlation between the anatomical variables of the ridges and masticatory efficiency in complete denture wearers. Overall, we found that for the maxillary arch the crest height and arch width influence the masticatory efficiency. For the lower arch, the ridge anatomy did not influence the masticatory efficiency of the individuals.

Unlike other studies, the present study used the sieve method to evaluate masticatory efficiency. The artificial food used in this method has a standard consistency, which influences the muscular performance, and the material is not affected by the solubilizing and enzymatic action of water and saliva; these factors contribute to the method's standardization and reproducibility properties $[15,16]$. For measurements of the anatomical features, the use of the drypoint compass allowed access to the most retentive areas without interferences, providing data with high reliability.

Residual ridge anatomy and masticatory efficiency were negatively correlated in most analyses, both in the maxilla and the mandible. This confirms that the greater the height, width, and size of the ridge and the length, width, and size of the arch, the smaller the chewed particles, and better masticatory efficiency. However, significant correlations were found only in the maxilla. This finding is probably because the maxilla has better bone support and more favorable fibromucosa to meet retention and stability requirements for an efficient mastication. In our sample, most of the patients had a somewhat resorbed residual ridge, which compromised the retention and stability of the prosthesis, affecting the masticatory performance.

The process of vertical bone resorption of the mandible is more accelerated than the maxilla in the long term. This difference probably caused the observed differences in retention and stability of the complete prostheses, justifying the negative and significant correlation between masticatory efficiency and crest height in the maxilla residual ridge with old $(p=0.026)$ and new prostheses $(p=0.041)$, which was not observed for the jaw [16].

The retention and stability required for complete dentures is dependent on physical phenomena (adhesion, cohesion, surface tension, atmospheric pressure, and salivary viscosity) provided by the shape of the residual ridge crest and the contact surface of the prosthesis base $[5,17,18]$. These factors are mediated by the salivary molecules that interact with these surfaces and promote the retention of the prosthesis, affecting the masticatory performance $[17,19]$. In the present study, $82.8 \%$ of the patients had a large maxillary ridge, while only $62 \%$ of the individuals had a large mandibular ridge, with the remainder consisting of small or medium ridges, which are more susceptible to the displacement of the prosthesis [5]. With displacement and consequent break of the salivary surface tension, the entrance of air beneath the denture interferes with the physical phenomena needed for its retention [17]. This situation probably caused the observed differences in the correlations for the jaw and maxilla.

A negative and significant correlation was also observed between maxillary arch width and masticatory efficiency assessed with the old prostheses, and a trend was found for the new prostheses. No correlation was observed for the mandible. The greater width of the maxillary arch, compared to the mandibular arch, allowed a larger contact surface between the denture base and the residual ridge. This situation helps the maxillary prostheses to counteract the lateral forces that occur during mastication, resulting in stability and balance, and consequently assisting in the retention of prosthesis [20].

The masticatory efficiency of the participants did not differ much between $\mathrm{T} 1$ and $\mathrm{T} 2$, probably because the time wearing the new prosthesis was not sufficient for complete adaptation and reprogramming of the neuromuscular system according to the new occlusal pattern [21,22]. In future evaluations of the same sample, masticatory efficiency could yield better results. However, our results corroborate other studies on the subject, in which the average masticatory efficiency is of $6.47 \mathrm{~mm}$ [23]. The masticatory efficiency of complete denture wearers is decreased compared to values of people with natural dentition, which is on average $3.32 \mathrm{~mm}$. In addition, some authors have shown that clinically satisfactory complete dentures have limitations and are poor substitutes for natural teeth $[4,10,23-25]$. On average, patients rehabilitated with conventional complete dentures need to chew 4 times more to achieve the same level of chewing of people with natural dentition [10].

Individual factors may also have interfered in the obtained results, such as the age of the patients [25]. The mean age of our sample was 67.9 years $( \pm 9.46)$, and at that age there is a natural decline in masticatory force, 
in addition to hyposalivation, which impairs prosthesis retention $[10,25,27]$.

Finally, the factors that determine the retention and stability of complete prostheses are interdependent; a preexisting healthy bone support, together with a resilient fibromucosa are fundamental [20]. In clinical practice, the dissatisfaction of many patients is related the lower denture and it can be assumed that complaints are associated with the lack of adaptation of the musculature to the new prostheses $[5,23,28]$.

\section{CONCLUSION}

In conclusion, the results of this study indicated that the greater the crest height and the arch width of the maxilla, the better the masticatory efficiency of the edentulous patient wearing complete dentures. For the mandible, the residual border anatomy had little influence on masticatory performance of complete denture wearers.

\section{Collaborators}

MFTP CAMPOS participated in the design, definition of intellectual content, literature search, and clinical and experimental studies. LA MELO participated in the design, definition of intellectual content, literature search, clinical study, data acquisition, data analysis, statistical analysis, manuscript preparation, manuscript editing, and manuscript review. RFF ARAUJO participated in the design, definition of intellectual content, literature search, and clinical and experimental studies. AKB MEDEIROS participated in the design, definition of intellectual content, literature search, and clinical and experimental studies. AFP CARREIRO participated in the design, definition of intellectual content, literature search, clinical studies, data acquisition, data analysis, statistical analysis, manuscript preparation, manuscript editing, and manuscript review.

\section{REFERENCES}

1. Mercier $\mathrm{P}$, Lafontant R. Residual alveolar ridge atrophy: classification and influence of facial morphology. J Prosthet Dent 1979;41:90-100. http://dx.doi.org/10.1016/00223913(79)90363-9

2. Pietrokovski J, Starinsky R, Arensburg B, Kaffe I. Morphologic characteristics of bony edentulous jaws. J Prosthodont 2007;16:141-7. http://dx.doi.org/10.1111/j.1532849X.2007.00165.x
3. Atwood DA. Reduction of residual ridges: a major oral disease entity. J Prosthet Dent 1971;26:266-79. http://dx.doi. org/10.1016/0022-3913(71)90069-2

4. Singhal S, Chand $P$, Singh BP, Singh SV, Rao J, Shankar $\mathrm{R}$, Kumar $\mathrm{S}$. The effect of osteoporosis on residual ridge resorption and masticatory performance in denture wearers. Gerodontology 2012;29:e1059-66. http://dx.doi.org/10.1111/ j.1741-2358.2011.00610.x

5. Ribeiro JA, Resende CM, Lopes AL, Farias-Neto A, Carreiro AF. The influence of mandibular ridge anatomy on treatment outcome with conventional complete dentures. Acta Odontol Latinoam 2014;27:53-7.

6. Carlsson GE, Omar R. The future of complete dentures in oral rehabilitation. A critical review. J Oral Rehabil 2010;37:143-56. http://dx.doi.org/10.1111/j.1365-2842.2009.02039.x

7. Koshino H, Hirai T, Ishijima T, Ohtomo K. Influence of mandibular residual ridge shape on masticatory efficiency in complete denture wearers. Int J Prosthodont 2002;15:295-8.

8. Ohki Y, Uchida T, Hayakawa I. Relationship between Masticatory Ability and Shape of Denture-supporting Area of Complete Denture Wearers. Prosthodont Res Pract 2004;3:25-32. http://dx.doi.org/10.2186/prp.3.25

9. Koshino H, Hirai T, Yokoyama Y, Tanaka M, Toyoshita Y, Iwasaki K, Sudo E. Mandibular residual ridge shape and the masticatory ability in complete denture wearers. Nihon Hotetsu Shika Gakkai Zasshi. 2008;52:488-93. http://dx.doi. org/10.2186/jjps.52.488

10. van der Bilt $A$. Assessment of mastication with implications for oral rehabilitation: a review. J Oral Rehabil 2011;38:754-80. http://dx.doi.org/10.1111/j.1365-2842.2010.02197.x

11.Slagter AP, Olthoff LW, Bosman F, Steen WH. Masticatory ability, denture quality, and oral conditions in edentulous subjects. J Prosthet Dent 1992;68:299-307. http://dx.doi. org/10.1016/0022-3913(92)90334-7

13. Oliveira NM, Shaddox LM, Toda C, Paleari AG, Pero AC, Compagnoni MA. Methods for evaluation of masticatory efficiency in conventional complete denture wearers: a systematized review. Oral Health Dent Manag 2014;13:757-62.

14. Carvalho PM, Castelo PM, Carpenter GH, Gavião MB. Masticatory function, taste, and salivary flow in young healthy adults. J Oral Sci 2016;58:391-9. http://dx.doi.org/10.2334/ josnusd.16-0135

15. Pietrokovski J, Harfin J, Levy F. The influence of age and denture wear on the size of edentulous structures. Gerodontology. 2003;20:100-5. http://dx.doi.org/10.1111/ j.1741-2358.2003.00100.x

16.van der Bilt A, Abbink JH. The influence of food consistency on chewing rate and muscular work. Arch Oral Biol 2017;83:105-10. http://dx.doi.org/10.1016/j.archoralbio.2017.07.011

17. Fontijn-Tekamp FA, Slagter AP, Van Der Bilt A, Van 'T Hof MA, Witter DJ, Kalk W, Jansen JA. Biting and chewing in overdentures, full dentures, and natural dentitions. J Dent Res 2000;79:1519-24. http://dx.doi.org/10.1177/002203450007 90071501 
18. Bláhová Z, Neuman M. Physical factors in retention of complete dentures. J Prosthet Dent 1971;25:230-35. http:// dx.doi.org/10.1016/0022-3913(71)90182-X

19. Barbenel JC. Physical retention of complete dentures. J Prosthet Dent 1971;26:592-600. http://dx.doi.org/10.1016/00223913(71)90083-7

20. Márton K, Boros I, Fejérdy $P$, Madléna $M$. Evaluation of unstimulated flow rates of whole and palatal saliva in healthy patients wearing complete dentures and in patients with Sjogren's syndrome. J Prosthet Dent 2004;91:577-81. http:// dx.doi.org/10.1016/j.prosdent.2004.03.031

21. Jacobson TE, Krol AJ. A contemporary review of the factors involved in complete dentures. Part III: support. J Prosthet Dent 1983;49:306-13. http://dx.doi.org/10.1016/00223913(83)90267-6

22. Farias-Neto A, Carreiro A F. Changes in patient satisfaction and masticatory efficiency during adaptation to new dentures. Compend Contin Educ Dent. 2015;36:174-77.

23. Eberhard L, Oh K, Eiffler C, Rammelsberg P, Kappel S, Schindler HJ, Giannakopoulos NN. Adaptation to new complete dentures-is the neuromuscular system outcomeoriented or effort-oriented? 2018;22:2309-17. http://dx.doi. org/10.1007/s00784-017-2331-8

24. van der Bilt A, Fontijn-Tekamp FA. Comparison of single and multiple sieve methods for the determination of masticatory performance. Arch Oral Biol 2004;49:193-8. http://dx.doi. org/10.1016/j.archoralbio.2003.08.004

25. Marcello-Machado RM, Bielemann AM, Nascimento GG, Pinto LR, Del Bel Cury AA, Faot F. Masticatory function parameters in patients with varying degree of mandibular bone resorption. J Prosthodont Res 2017;61:315-23. http:// dx.doi.org/10.1016/j.jpor.2016.12.002

26. Ikebe K, Matsuda K, Kagawa R, Enoki K, Yoshida M, Maeda Y, Nokubi T. Association of masticatory performance with age, gender, number of teeth, occlusal force and salivary flow in Japanese older adults: is ageing a risk factor for masticatory dysfunction? Arch Oral Biol 2011;56:991-6. http://dx.doi. org/10.1016/j.archoralbio.2011.03.019

27. Peyron MA, Woda A, Bourdiol P, Hennequin M. Age-related changes in mastication. J Oral Rehabil 2017;44:299-312. http://dx.doi.org/10.1111/joor.12478

28. van Kampen FM, van der Bilt A, Cune MS, Fontijn-Tekamp FA, Bosman F. Masticatory function with implant-supported overdentures. J Dent Res 2004;83:708-11. http://dx.doi. org/10.1177/154405910408300910

Received on: 28/4/2020

Final version resubmitted on: 31/8/2020

Approved on: 15/9/2020 